\title{
Green Infrastructure, Green Stormwater Infrastructure, and Human Health: A Review
}

\author{
Pongsakorn Suppakittpaisarn $^{1} \cdot$ Xiangrong Jiang $^{2}$ - William C. Sullivan ${ }^{2}$
}

Published online: 22 November 2017

(C) Springer International Publishing AG 2017

\begin{abstract}
Purpose of the Review In a growing trend, cities around the world have been installing Green Infrastructure (GI) in the form of vegetated landscapes that provide ecological benefits such as stormwater management, wildlife habitats, and temperature moderation (Tzoulas et al. Landsc Urban Plan. 61(3):11, 2007). Some GI, such as trees and green spaces, have positive impacts on human health. It is less clear how newer types of GI, such as rain gardens, green roofs, and bioswales, impact human health. These newer GI types are called Green Stormwater Infrastructure (GSI). Planners and designers need to know the extent to which GSI impacts humans. This systematic review does exactly that -we explore the published evidence regarding the relationships between GI and human health.

Recent Findings We identified 55 peer-reviewed articles addressing these issues. Familiar types of GI, such as trees and green spaces, were found to be beneficial to the body (cardiovascular system, cortisol regulation, and pregnancy health), mind (attention capacity and mental health), and behavior (lower crime, better self-regulation, and more pro-social behaviors). We found much less research exploring the impacts of GSI on health.
\end{abstract}

This article is part of the Topical Collection on Effects of Landscape Structure on Human Wellbeing

Pongsakorn Suppakittpaisarn

psuppak@gmail.com

1 Department of Plant Sciences and Soil Sciences, Faculty of Agriculture, Chiang Mai University, Suthep Rd, Tambon Suthep, Amphoe Mueang Chiang Mai, Chiang Mai 50200, Thailand

2 Department of Landscape Architecture, University of Illinois at Urbana-Champaign, 610 E Lorado Taft Dr, Champaign, IL 61820, USA
Summary Our findings show that for some of the specific categories of GI, such as trees, considerable evidence exists on the impacts on human health. For other categories, such as rain gardens, green roofs, or biodiverse plantings, however, there is scant evidence of a health impact. We believe it is likely that these forms of GI do impact human health and that the reason for the scarcity of evidence is that few careful studies have examined the impacts of newer forms of GI on specific human health outcomes. Future researchers should investigate the health effects of type, dose, frequency, and duration of exposure to GI and GSI.

Keywords Green infrastructure - Green stormwater infrastructure $\cdot$ Human health $\cdot$ Well-being $\cdot$ Systematic lit review $\cdot$ Built environment

\section{Introduction}

Cities around the world are installing Green Infrastructure (GI) to improve the health of urban ecosystems and manage stormwater. GI includes well-known aspects of urban nature, such as tree-lined streets and parks, as well as newer, emerging landscape elements, such as rain gardens and green roofs. Although we know that there are significant ecological benefits of GI, we know less about the extent to which different kinds of GI impact human health.

\section{Health Benefits of Green Infrastructure (GI)}

For 30 years, scholars have assessed the health benefits of urban nature $[1-3,20]$. Although there are literature reviews exploring this topic, most citations in those reviews focus on studies published earlier than $2010[4,5]$. One recent review focused on the relationship between GI and the environmental conditions that might influence health but touched little on the 
direct health benefits [6]. In this review, we address the following questions: what are the mental, physical, and social benefits of GI? Which of these benefits are well-established, and which need more support? To what extent do the findings generalize to other people and settings than were presented in the experiment? Such a review would aid policy makers and health professionals as they work with cities to develop healthy environments and health guidelines.

\section{Types of GI that Produce Health Benefits}

It seems clear that some forms of GI such as trees and parks promote health, but we need to understand whether the emerging forms of GI (e.g., rain gardens, bioswales) promote health to the same degree. These new types of GI are called Green Stormwater Infrastructure (GSI) and we are less confident about how GSI impacts human health. Some studies have suggested that dense, wild vegetation can make people feel uncomfortable because it looks like it might harbor harmful creatures such as snakes and spiders [7]. Such settings are unlikely to promote human health. There are more questions regarding how GI can impact health, such as density levels and types of exposure. To what extent does the density of GI or the kind of exposure to GI matter? Without addressing these questions, we risk installing types of GI that are less than supportive for humans.

To address these questions, we conducted a systematic literature review to understand the relationships between types of GI and human health. We answer the following questions:

- What are the documented health benefits associated with GI?

- To what extent do different types and amounts of GI exposure impact human health?

\section{Methods}

To answer these questions, we conducted a systematic review. In the following sections we explain how we conducted the literature search, created inclusion criteria, selected, extracted, and appraised the studies, and synthesized the data.

\section{Literature Search}

From March 2015 to May 2016 and December 2016 to January 2017 we searched peer-reviewed articles published from January 2011 to January 2017 on PubMed, Scopus, and Web of Science. We looked for the literature using terms from two categories of keywords. The first category contained keywords related to GI, including "green infrastructure", "trees", "street trees", "window views", "green stormwater infrastructure", "green spaces”, "open spaces", "green views”, "views of nature", "parks", "bio-retention", "rain gardens", "bioswales", "green roofs", and "flowers". The second category contained keywords related to health: "human health", "well-being", "attention restoration", "stress recovery", "social cohesion", "pro-social behavior", "mental health", "crime", and "social capital". We paired words from these two categories separated by the word 'AND'. For example, when we searched for a relationship between rain gardens and attention restoration, our search terms were "'rain gardens' AND 'attention restoration"'. All possible combinations of GI keywords and health keywords were used.

Because we found few studies exploring how GSI (such as rain gardens and bio-retention) impact human health, we expanded both our 'health' terms and our 'GI' terms to include terms related to how people perceive GSI, including "feelings", "preference", "perception", and "happiness index", because perceptions and preference are a good indicator of how well people might function in and respond to environments [1, 8]. We also included characteristics of green spaces that are common in GSI designs, including "native plants", "wetland", and "biodiversity". The terms were combined in the same manner as the initial search, and all possible pairs were matched.

When a search with these various combinations of keywords identified a literature review, we searched for peerreviewed articles that cited those literature reviews. We also looked at important theories exploring the relationship between nature and human health (such as Kaplan's Attention Restoration Theory (ART), which explains how people have more attention capacity after viewing nature) to better understand the studies we found that cite these seminal works.

\section{Inclusion Criteria}

We searched for articles that appeared in peer-reviewed journals, published in English, during January 2011 to January 2017 reporting health outcomes from GI or any representations of GI, such as photographs and videos. The health outcomes were objective measures, such as blood pressure or Digit Span Forward Score. Self-reported studies were excluded from this review in large part because of the sheer quantity of such articles during the study period (more than 730 published papers). If the studies had multiple measures, the selfreported results were not included. We included all experimental designs, such as randomized controlled trials, quasiexperimental studies, and natural experiments. We also included observational studies.

Because studies of GSI (e.g., rain gardens, bio-retentions) and human health benefits were rare, we included studies exploring these forms of GSI and any health and well-being indicator. We accepted self-report results for these studies. These results were analyzed separately. 
If the health outcomes were related to behaviors, we selected the studies in which the behaviors were indicators of physical, mental, and behavioral health, such as helpfulness, social cohesion, or aggression. We excluded the impact of GI on the environmental influence on health, such as water quality or air quality.

\section{Study Selection, Extraction, and Appraisal}

We entered data regarding all articles that passed the inclusion criteria in Endnote 7 [9]. To obtain meaningful information from the articles, we used standardized data extraction sheets to extract content including study design, validity, types of GI, population, methods, and types of exposure or engagement with GI. We used the quality assessment process suggested by Centre for Reviews and Dissemination's Guide for Systematic Review (2009), the Critical Appraisal Checklist from Critical Appraisal Skills Program (2013), and the Quality Assessment Tool for Quantitative Studies from the Effective Health Practice Project (2013) to assess the robustness, validity, and generalizability of each study. These appraisal checklists have been used in other systematic reviews [10]. The studies that did not pass the appraisal standards were excluded.

\section{Data Synthesis}

After the selection process, we organized the results based on types of health outcomes and types of GSI and identified from them what we already know, what we found promising, and what is missing from these studies.

\section{Results}

Fifty-five articles fit all of the inclusion criteria. Most studies originated from western countries, such as the USA, Canada, and the UK, in part because we searched for articles published in English (Fig. 1). Table 1 displays the population groups of the studies, Table 2 the methods used for the studies, and Table 3 the types of GI studied.

Our results are organized into two sections: (1) the health benefits of GI; and (2) the relationship between different types of GI and human health.

\section{Question 1: What are the Documented Health Benefits Associated with GI?}

Three health themes emerged from our search: Body, Mind, and Behavior. Figure 2 summarizes the health benefits associated with GI, and Table 4 indicates which studies address each health outcome.

\section{How Does GI Benefit Human Bodies?}

Previous studies have suggested that contact with nature and natural elements improves physical health [5, 55, 56]. One of the underlying theories is that modern urban life causes stress [57], and chronic stress leads to physical sickness [58]. Stress Reduction Theory (SRT), sometimes known as PsychoEvolutionary Theory, posits that people recover from stress more effectively when they are exposed to a more natural environment [59], thus reducing the potential of stressrelated illness such as cardiovascular diseases and other chronic health issues $[58,60]$. In our research, we found that GI is linked to cardiovascular health, healthier patterns of cortisol secretion, better pregnancy and birth outcomes, and other physical health benefits. These are considered in detail in the following sections.

\section{Cardiovascular Health}

Eleven studies identified cardiovascular health benefits of GI. Some studies associated GI exposure with long-term cardiovascular health, such as lower risk of mortality by cardiovascular disease [15] and healthier base-level blood pressure [16, 17]. The association between GI and cardiovascular health has been observed in women during early pregnancy [16] and in children [17], even when other possible confounders are taken into account. Other studies showed the short-term effects of GI exposure through experimental settings. These studies reported that viewing a video of GI is associated with higher systolic blood pressure within a healthy range, an indicator that the participants are invigorated [18], and with a steadier heart rate [11-13]. One study found that participants returned to their neutral blood pressure faster after a stressful experience if they watched a video of grasslands and trees beforehand [14].

These and previous studies support the notion that people who expose themselves to natural environments suffer less from chronic stress-related illness. They show that GI exposure is associated with better cardiovascular health both in the short- and long-term. Because of the consistency of this evidence, we are confident that GI exposure is associated with better cardiovascular health.

\section{Cortisol Patterns and Other Stress Indicators}

Similar results have been reported when the assessment of stress comes from measuring cortisol. Cortisol is a hormone released when humans are stressed. While cortisol is beneficial in the short-term, high levels of cortisol over a prolonged time period can lead to a range of negative health outcomes, such as obesity, cardiovascular diseases, and gonad dysfunctions [60, 61]. Four studies linked GI exposure to healthier cortisol levels. An experimental study found that stress-induced cortisol in 


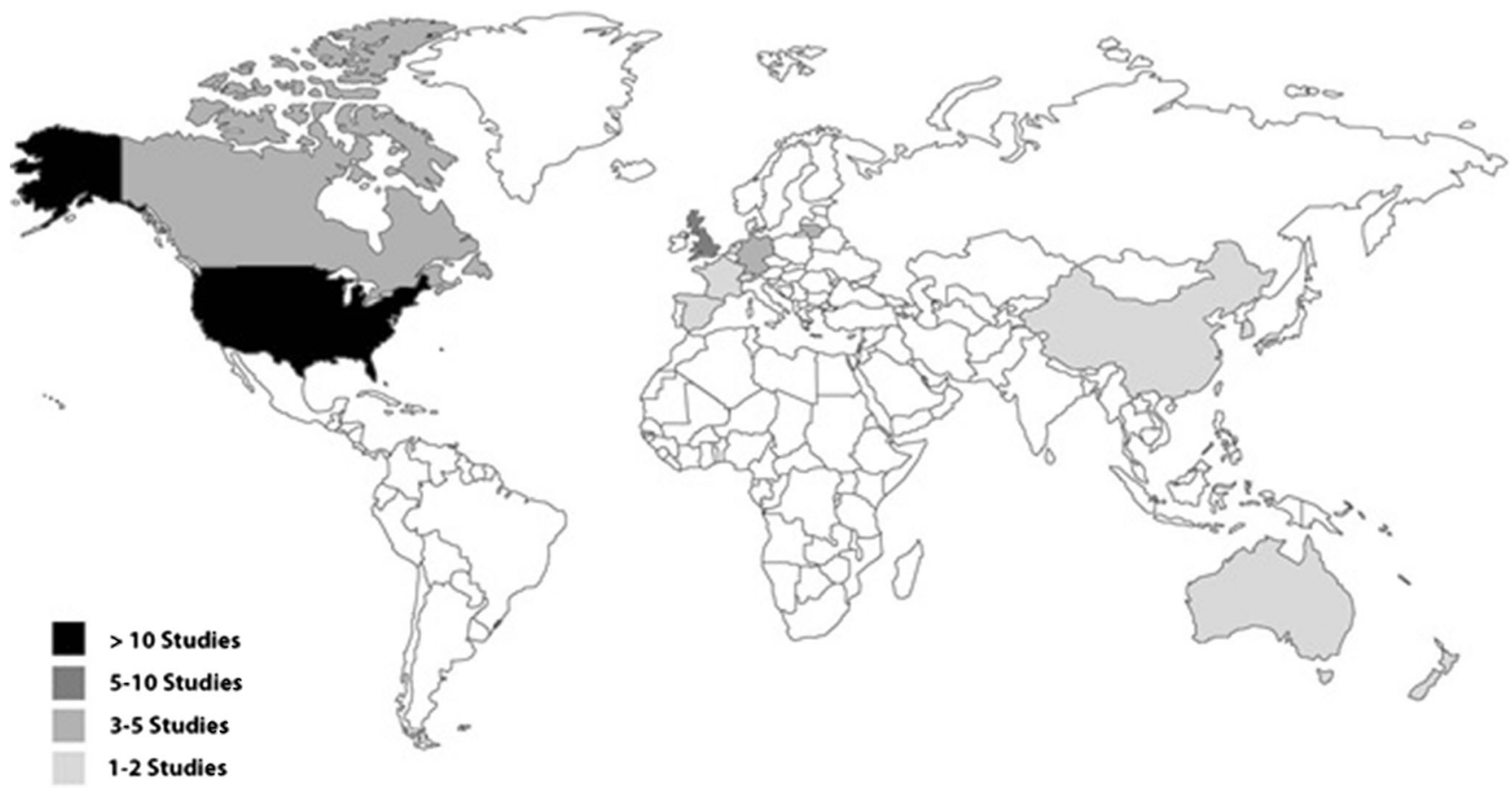

Fig. 1 Locations of the studies

men can be reduced by viewing videos of street trees of varying density [20]. Other observational studies investigated depressed urban communities and found that higher densities of trees around residential neighborhoods were associated with heathier cortisol patterns, both in the saliva [21, 22] and hair [19] of the residents; that is, people who live in neighborhoods with higher tree density levels have a more regular diurnal cortisol pattern [21] and collect less cortisol residue in their hair [19]. Some studies showed differences between men and women. In the study by Jiang et al. [20], salivary cortisol was correlated with GI exposure for men but not for women. This, the authors explained, might be because of the different patterns of cortisol secretion between the sexes. Another study found that in settings with little to no GI, women had a condition known as hypocortisolemia, meaning that their cortisol levels were too

Table 1 Population groups of the studies. Some studies included more than one characteristic in their population

\begin{tabular}{ll}
\hline Population & Number of studies \\
\hline General adults & 25 \\
Children and adolescents & 11 \\
Young adults/college students & 8 \\
Office workers & 5 \\
Low income people & 5 \\
Newborns & 4 \\
Racial minorities & 2 \\
Older adults & 1 \\
Pregnant women & 1 \\
\hline
\end{tabular}

low. It is interesting to note that this condition did not occur for women in neighborhoods with more GI [21].

The evidence demonstrating an association between GI and cortisol secretion is new and promising. It supports Ulrich's existing SRT by showing that people who are exposed to natural elements - even in urban settings - are more likely to recover from stress more effectively [7, 56, 57]. Future research might explore the interaction between exposure to GI and gender in cortisol secretion.

Other studies examining the extent to which exposure to GI impacts stress have focused on two objective measures of stress. Three experiments report that as exposure to GI increases participants experience healthier parasympathetic responses to stress measured by skin conductance and skin temperature $[11,13,20]$.

Table 2 Methods used in the studies

\begin{tabular}{ll}
\hline Methods & Number of studies \\
\hline Observational studies & 33 \\
Experiments & 13 \\
Field experiment $^{\mathrm{a}}$ & 1 \\
Survey & 7 \\
Interview & 1 \\
\hline
\end{tabular}

${ }^{\text {a }}$ Note the difference between field experiment and experiment: a field experiment is an experiment performed in a real situation, where confounding factors may not be fully controlled 
Table 3 Types of Green Infrastructure studied

\begin{tabular}{ll}
\hline GI types & Number of studies \\
\hline Trees & 23 \\
Green spaces & 20 \\
Rain gardens and bioswales & 1 \\
Green roofs & 7 \\
Other vegetation components & 4 \\
\hline
\end{tabular}

GI Green Infrastructure

\section{Pregnancy and Birth Outcomes}

Five studies reported links between GI exposure and healthier pregnancy and birth outcomes. Residential proximity to GI is associated with higher term birth weight in three studies [23-25], larger head circumference [24], lower risk of the baby being too small for its gestational age [23, 26], and healthier blood pressure in pregnant women [16]. These relationships persist even after air pollution, noise, and accessibility by walking are taken into account [23].

Although the evidence linking exposure to GI with positive pregnancy outcomes is promising, the mechanisms remain unclear. Is stress the main mediator in this relationship? To what extent might other factors, such as physical activity, mediate the relationship? Future research could explore the extent to which exposure to varying levels of GI influences pregnancy and birth outcomes.

\section{Other Physical Health Benefits}

Aside from the benefits described earlier, other benefits of exposure to GI include reduced incidents of respiratory diseases and allergy rates in rural areas [15, 27, 62], lower rates of obesity, reductions in body mass indexes [28, 30, 31], and lower mortality rates $[15,29]$. We found this evidence promising, but more studies are needed to replicate these findings. One study about residential tree density and children's

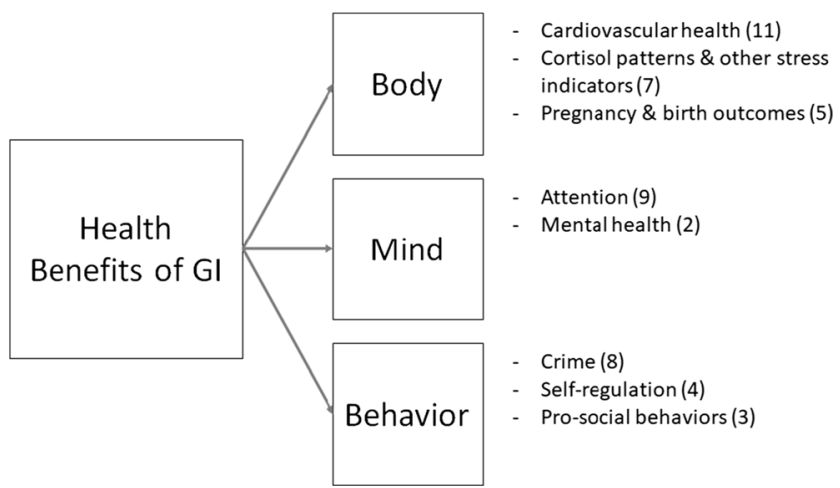

Fig. 2 Three categories of health benefits associated with Green Infrastructure (GI) reported in recent literature. For each category, we list the three most reported health benefits allergies and respiratory diseases in Germany reported conflicting results: researchers reported that tree density was associated with lower allergy rates in Northern Germany but higher allergy rates in Southern Germany [27]. The author speculated that the confounder might be the level of urbanization. This incongruence should also be explored further.

\section{How Does GI Benefit Humans’ Minds?}

We categorized the benefits of GI on human minds with respect to attention, mental health, and other benefits on humans' minds.

\section{Attention}

The relationship between exposure to settings that include nature and the improvement in the ability to pay attention is well-established [5, 10, 63]. Improvement in attentional capacity after exposure to GI is widely attributed to a process described by ART. ART posits that being in nature (even urban settings with vegetation) restores one's ability to pay attention, allowing humans to function and make decisions more effectively than when they are mentally fatigued [64].

Five studies reported a significant positive association between exposure to GI and attention measured through shortterm memory tests. The studies took place in laboratory or field settings and compared the relationship between viewing or walking in open green spaces and memory. Short-term memory was tested using Digit Span Tests [11, 13, 32, 33]. One study investigated the association of exposure to GI and long-term memory by asking participants about the details of the room in which the experiment took place 1 week earlier. Individuals who had been randomly assigned to watch videos with higher levels of GI recalled more details of the experiment room [18]. Another study reported that the relationship between GI and short-term memory extended to individuals with depression [32].

Four studies report a positive relationship between exposure to GI and attention capacity measured through a variety of attention tasks such as the Trail Maker Tests, Operation Span Task, Change Detection, and Attention Network Tasks [33-35]. Viewing a GI video has also been shown to significantly help office workers respond to visual stimulants, such as pressing a button when a dot appears on screen, more quickly [18].

These studies give us confidence that exposure to GI can improve cognitive functioning by improving short-term memory and our ability to pay attention. GI's impact on long-term memory is an area ripe for further research. Researchers might also explore is the extent to which exposure to GI helps delay cognitive deterioration associated with aging. 
Table 4 Summary of health outcomes from Green Infrastructure

\begin{tabular}{|c|c|c|c|}
\hline Categories & Health benefits & Measures & References \\
\hline \multirow[t]{16}{*}{ Body } & \multirow[t]{4}{*}{ Cardiovascular health } & ECG & {$[11]$} \\
\hline & & Heart rate variability & {$[12-14]$} \\
\hline & & Cardiovascular diseases & {$[15]$} \\
\hline & & Blood pressure & {$[13,14,16-18]$} \\
\hline & \multirow{4}{*}{$\begin{array}{l}\text { Cortisol patterns and other stress } \\
\text { indicators }\end{array}$} & Hair cortisol & [19] \\
\hline & & Salivary cortisol & [20-22] \\
\hline & & Skin temperature & {$[13]$} \\
\hline & & Skin conductance & {$[11,13,20]$} \\
\hline & \multirow[t]{2}{*}{ Pregnancy and birth outcomes } & Birth outcomes & {$[23-26]$} \\
\hline & & Pregnancy health & [16] \\
\hline & \multirow[t]{6}{*}{ Other } & Respiratory diseases and allergies & {$[15,27,28]$} \\
\hline & & Mortality rate & {$[15,29]$} \\
\hline & & Obesity rate and BMI & [29-31] \\
\hline & & Memory tests & {$[11,13,18,32,33]$} \\
\hline & & Trail making test B & [34] \\
\hline & & Reaction time & [18] \\
\hline \multirow[t]{8}{*}{ Mind } & \multirow[t]{5}{*}{ Attention } & Sustained attention & {$[35]$} \\
\hline & & Color stroop test & {$[36]$} \\
\hline & & Performance under chronic depression & {$[32]$} \\
\hline & & School performance & {$[37]$} \\
\hline & & Cognitive development & {$[38]$} \\
\hline & \multirow[t]{2}{*}{ Mental health } & Anxiety + mood disorder treatment & {$[39]$} \\
\hline & & Antidepressant prescription rates & {$[40]$} \\
\hline & Other & Emotional resilience & {$[41,42]$} \\
\hline \multirow[t]{6}{*}{ Behavior } & Crime & Percentage of crime reduction & {$[43-50]$} \\
\hline & \multirow[t]{2}{*}{ Self-regulation } & Behavioral resilience & {$[41,42]$} \\
\hline & & Impulsivity control and self-regulation & {$[36,51]$} \\
\hline & \multirow[t]{3}{*}{ Pro-social behaviors } & Helpful behaviors & {$[52]$} \\
\hline & & Generous behaviors & {$[53]$} \\
\hline & & Lower aggressive tendencies & {$[54]$} \\
\hline
\end{tabular}

$B M I$ body mass index, $E C G$ electrocardiogram

\section{Mental Health}

In addition to improving cognitive functioning, there are hints that exposure to GI is associated with a lower risk of depression, anxiety, and mood disorders. Two studies reported an association between GI and mental health. They found that living near GI is associated with a lower risk of receiving anxiety mood disorder treatments [39] and a lower rate of prescriptions for antidepressant medication [40]. Because of the nature of the studies, they only investigated the area-levels of the relationship, which means that they cannot consider individual's income and medical histories.

While more evidence is needed to explore and eliminate confounding factors, such as the length of the symptoms, the accessibility to treatments, poverty, and a host of other factors, these studies provided promising suggestions that GI is positively correlated to mental health.

\section{Other Benefits on Humans' Minds}

In addition to the growing body of evidence demonstrating that exposure to GI has positive impacts on attention and is linked to better mental health, there are hints of other benefits. In children, exposure to GI is linked to cognitive development [38], a reduction in emotional problems [41], and an improvement in school-related performance [37]. Future research should try to replicate these findings in different settings to gain more confidence in them.

\section{How Does Exposure to GI Impact Human Behaviors?}

Past research has suggested a link between GI and less antisocial behavior $[2,3]$. One explanation for this relationship is ART. ART posits that contact with nature improves one's ability to employ top-down attention (what, in layperson 
terms, we often call 'paying attention'). When we have a greater reserve of top-down attention, we have better control of our behavior and are more thoughtful and reasonable. Because people are more reasonable, they are less likely to do something they might regret later such as acting violently; they might also be more friendly and helpful toward each other [64]. In our search, we found that GI is linked to three main behavioral benefits: lower crime, increased self-regulation, and greater likelihood of pro-social behaviors.

\section{Crime}

Eight studies linked exposure to and availability of GI with lower crime rates. The findings held for property crime (e.g., vandalism, burglary, robbery), drug crime (e.g., uses of narcotics), and violent crime (e.g., assaults, sexual assaults, gun assaults) [43-50]. It is notable that while GI is consistently associated with lower-violence crimes, crimes against property sometimes increase after GI installation [49]. The authors of this article do not provide any suggestions regarding why that might be the case.

These studies support the finding that trees are associated with lower crime rates, a finding that was first reported long before this review $[3,65,66]$. Hence, we can be confident that at least some types of GI (mainly trees and open spaces with trees) are associated with lower crime rates. Future studies might investigate the effects of different density levels of different vegetation and GI types on crime.

\section{Self-Regulation}

Four studies linked exposure to GI with greater self-regulation and ability to control oneself against impulsive decisions. This relationship might be explained by the ART. People who can focus better have a better control of their behaviors [67]. One study showed that children who had access to GI had fewer conduct and peer issues and hyper-activity problems [41]. Experimental studies found that people who saw GI images and videos controlled their impulses better than those who did not $[36,51]$. One study also showed that short-term exposure to GI had a positive impact on impulse control, which is a factor in self-regulation [36].

More studies are needed to clarify the relationship between GI and self-regulation. Previous studies showed that longterm exposure to greenness can mitigate symptoms of children with attention-deficit hyperactivity disorder (ADHD) [68]. These findings are important because we need to control impulses in everyday life. While we understand that exposure to GI can help control impulses in short-term behaviors, we wonder whether exposure to GI help regulate long-term behaviors that are bad for health, such as smoking, drinking, or eating unhealthy food?

\section{Pro-Social Behaviors}

Pro-social behaviors are good indicators of health [69]. There has been evidence in previous studies that exposure to GI increases social ties among neighbors [70] and three articles reported that exposure to GI was linked with pro-social behaviors. A field experiment reported that after walking through a park, participants were more likely to inform a stranger who had dropped their glove [52]. Another article explored how aggressive tendencies were influenced by exposure to nature. It reported that the aggressive tendencies changed after viewing environments with higher levels of security and resources (some images contained GI while other images did not). People expressed less aggression in resourcerich environments that felt safe, such as a savannah-like landscapes, but more aggression in environments with fewer resources and security, such as a desert. The authors suggested that the impact had more to do with resource availability, but the level of security played a role in the behavior and should not be overlooked [54]. Another study showed that children displayed more generous behaviors after being surrounded by tall trees [53].

These findings are congruent with past research that linked types of GI with stronger social ties [65]. More research is needed to establish stronger links between GI and pro-social behaviors, and many questions remain unanswered. For instance, all three of the Guégen et al. [52], Piff et al. [53], and $\mathrm{Ng}$ and Chow [54] studies reported different behaviors from two groups of participants. That means that we still did not know whether a person's tendency to exhibit pro-social behaviors can be influenced by GI exposure.

Promising evidence exists that exposure to GI is linked with lower crime rates, better self-regulation, and pro-social behaviors. Overall, we need more information regarding how a host of demographic and social factors interact with exposure to GI to influence these outcomes.

\section{Question 2: To What Extent do Different Types and Amounts of GI Exposure Impact Human Health?}

There is considerable evidence that exposure to trees and green spaces is beneficial for human health-and, indeed, the body of evidence is growing. Some studies have focused on the density of only trees, which may include street trees and trees in residential properties as well as trees in public open spaces, while others investigated green spaces such as parks and urban forests, which include sidewalks, grasses, plantings, and, most of the time, trees. For the newer types of GI, such as rain gardens, bioswales, and green roofs, we have much less information; only two studies were found. In this section, we examine the extent to which varying types and forms of exposure of GI are linked to human health benefits. Figure 3 provides a summary of the associations between the types of 
Fig. 3 Summary of the associations between the types of Green Infrastructure (GI) and the type of benefits

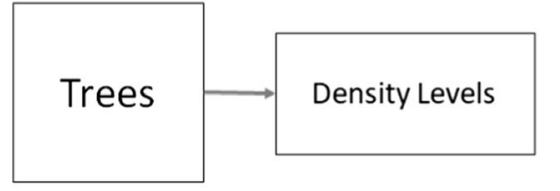

- Lower crime (5)

- Optimal cortisol levels (4)

- Pregnancy and birth outcomes (4)

- Cognitive development and Performance (2)

- Lower blood pressure (2)

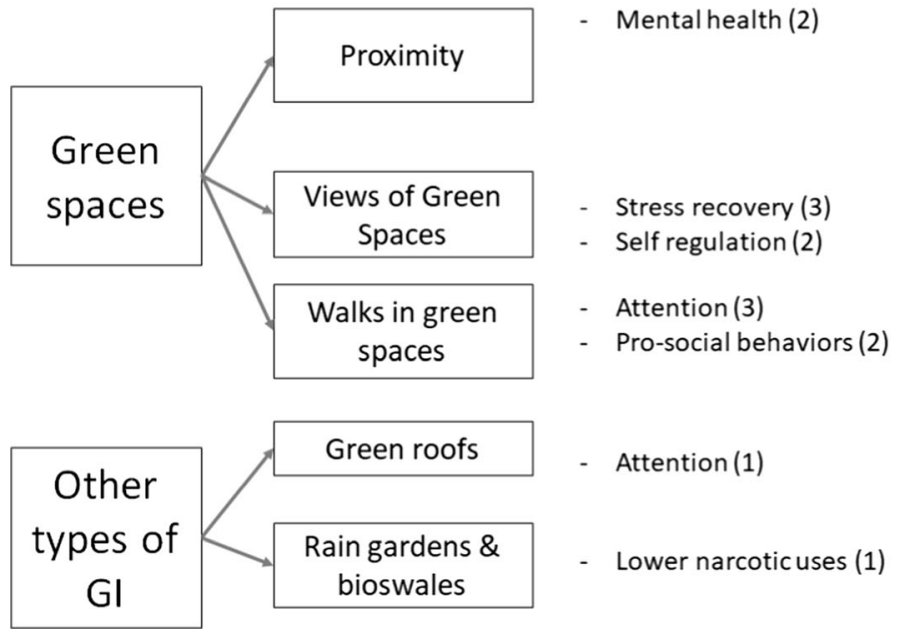

GI and the type of benefits. Table 2 identifies the measures various authors have used to measure the relationships among GI and human health. Table 5 summarizes the types of GI and forms of exposure.

\section{Tree Density}

Previous research has established that trees provide a wide variety of health benefits [55]. The presence and density of trees has been used to explore such benefits [2, 3, 65, 72]. Several theories explained why trees can benefit human health. First, in Psycho-Evolutionary Theory, we learned that humans evolved around savannah landscapes which combine trees with clear open spaces. Trees provided survival tools to our human ancestors and were their homes; thus, humans can relax and de-stress around well-placed trees [55]. The Reasonable Person Model also posits that people are more likely to be reasonable around the supportive environment; thus, tree density can make people more reasonable and social, leading to fewer violent social interactions [73]. Furthermore, the biological functions of trees might reduce some air pollution, leading to lower rates of respiratory diseases [74].

For a few decades we have had good evidence that exposure to some trees is better than to no trees, but we had less solid information on the impact of varying densities of trees. However, with the technology to investigate tree density such as satellite imagery, recent studies have provided a clearer relationship between tree density and human health.

Tree density is positively associated with lower crime rates [43, 44, 47, 48, 50], more optimal cortisol patterns [19-21, 75], lower blood pressure [16, 17], lower rates of obesity [62], lower allergy rates [27], higher cognitive development and performance [37, 38], lower prescription rates of antidepression medication [40], and better pregnancy outcomes [23-26].

However, most of the studies are correlational studies, considering linear relationships or categorical outcomes, and thus, the form of the association has been unclear. In seeking the form of the nature-health relationship, only one study looked
Table 5 Summary of the types of Green Infrastructure that are associated with human health

\begin{tabular}{lll}
\hline GI types & Forms of exposure & References \\
\hline Trees & Tree density & {$[15,17,19-28,37,40,42-44,47,48,50,62]$} \\
Green spaces & Proximity & {$[16,25,29-31,39,41,42]$} \\
& Walking in green spaces & {$[29,31-33,52]$} \\
& Views of green spaces & {$[11,13,14,18,36,51]$} \\
Other types of GSI & Views of green roofs & {$[35]$} \\
& Presence of rain gardens/bioswales & {$[71]$} \\
\hline
\end{tabular}

GI Green Infrastructure, GSI Green Stormwater Infrastructure 
at the form of the relationship by studying varying eye-level tree density with stress recovery in men and found that the relationship was a bell curve. That is, participants recover from stress increasingly better as the tree density they view becomes greater; however, at $60 \%$ tree density, the more dense the trees became the less effectively the participants started to recover from stress [20]. This research gives us more confidence that greater tree density can lead to a variety of health improvements.

While there is growing evidence of the relationship between trees and health outcomes, a large body of research is still needed to answer more questions about this relationship. We need more research on the impact of varying doses, frequency of exposure, and duration of exposure to trees and other types of GI on human health [76]. We also need to improve our understanding regarding the form of the relationship.

\section{Green Spaces}

It is important to consider the impact of green spaces, such as parks, school grounds, urban forests, and other areas, on human health because, unlike residential plantings and street trees, these spaces are public destinations; they are the spaces in which people who might not be able to afford it otherwise can spend time in and reap benefits of nature [77]. Aside from the benefits of the trees in open spaces, green spaces have some unique benefits. For example, it is a place where people can engage in physical activities and passive recreation [78]. Because of the layers of plant materials present in most green spaces, people usually experience soft fascination within the place. Soft fascination, according to Kaplan's ART, can help people regain some attention capacity and self-regulation [64, 79]. There are three main categories of measures used to examine green spaces: proximity to green spaces, views of green spaces, and walks in green spaces.

\section{Proximity}

Proximity to green spaces is one of the most popular measures of green space exposure. Six studies linked the distance between home and green spaces to health outcomes. The closer a person lives to a green space, the more likely they are to be gain long-term health benefits. These outcomes came from studies of pregnant women [42], newborn children [16], school-aged children [31, 42], and adults [29, 39]. The health outcomes associated with the proximity to green spaces include mental health [39, 42], pregnancy outcomes [25], blood pressure [16], lower rates of obesity [31], and lower mortality rates [29].

Most of the proximity measures are determined by satellite images; thus, some information about those green spaces could not be acquired. Also, some of those green spaces might not be public or accessible to the residents, and thus it might not accurately represent how close people are to accessible green spaces. These studies also did not compare the condition or size of each open space. Future research should investigate whether the relationships would be stronger when these factors are considered.

\section{Views of Green Spaces}

Seven experimental studies found viewing green spaces impacts health outcomes. Three studies investigated the impact of viewing videos of green spaces $[11,18,20]$ while three other studies investigated the impact of viewing green space images [14, 36, 51]. One study investigated the impact of window views looking out onto open green spaces [13]. All of these studies investigated only two to three categories of views: views of green spaces, views of urban areas, or no view at all. The views to green spaces and to urban settings differed in each study in size and ways of exposure. The health benefits that derive from views of green spaces include better selfregulation [18, 51], recovery from acute stress [11, 14, 20], and attentional functioning [11, 13, 18].

\section{Walks in Green Spaces}

Compared with simply viewing landscapes, walking in green spaces allows more sensory immersion. Five studies linked walking in green spaces with better health outcomes. These green spaces included city parks $[32,33,52,80]$ and urban forests [34]. Most of the studies were experimental and compared the effects of walking in green spaces and urban spaces on health outcomes [32-34, 80]. One study was a field experiment investigating the effects before and after a walk in a park [52]. The health benefits associated with walks in green spaces include better capacity to pay attention $[32,33,80]$ and a greater tendency for pro-social behaviors $[52,53]$.

Overall, this set of results is congruent with previous studies showing that exposure to green spaces provides physical and mental health benefits. Because most of these studies compared the presence of green spaces with spaces with no vegetation, there is a great deal that we do not know about exposure to such spaces. Future research should investigate the types or quality of these green spaces, along with other issues related to exposure such as dose of nature, frequency of exposure, and the duration of exposure [76].

\section{Other Types of GI}

Compared with trees and green spaces, we found little evidence in the published literature regarding the relationship between the newer types of GI (all types of GSI [71]), such as rain gardens, bioswales, and green roofs, and human health. We found two studies linking these newer types of GSI to 
human health. One experimental study linked views of green roofs with a health outcome: participants who viewed green roofs for 40 seconds performed better on sustaining attention [35]. Another experiment found that, compared with the control neighborhoods, narcotics use was reduced in neighborhoods that implemented rain gardens and bioswales. The author suggested that by bringing GSI to the streets, the neighborhood looked more cared for, and thus people did not go out and use narcotics in public [71].

By expanding our search to include preference and perception and to look at planting characteristics of GSI, we found several more sources relating newer types of GI and urban vegetation to health and well-being indicators (Fig. 4; Table 6).

\section{Green Roofs}

Five studies investigated perceptions, preference for, and wellbeing indicators of green roofs. On average, participants preferred green roofs over roofs without vegetation [82-84] and rated them more restorative and more likely to increase positive moods than barren roofs [82]. These studies reported different findings regarding the kind of green roofs people preferred: tall grass $[82,85]$ versus succulent plants [83]. They agree, however, on one notion: attractive green roofs compliment the surrounding architecture $[82,83]$. One qualitative study examined the extent to which green roofs are restorative to humans and reported that individuals who saw green roofs as a part of nature were more likely to feel as if the roofs were restorative [84]. A notable study from Hong Kong provided evidence that, compared with barren roofs, green roofs are associated with lower counts of mosquitoes, thus reducing health risks for mosquito-borne diseases [81].

\section{Other Vegetated Components of Green Stormwater Infrastructure}

We expanded our search to include any type of urban vegetation, ecological planting, or landscape improvements to see what evidence might inform ways to design GSI and found
Table 6 Relationships between Green Stormwater Infrastructure and human health and well-being indicators

\begin{tabular}{lll}
\hline Types of GSI & Outcomes & References \\
\hline Green roofs & Lower mosquito count & {$[81]$} \\
& More preferred & {$[82-85]$} \\
& Perceived as restorative & {$[84]$} \\
Other & Steadier heartbeat & {$[12]$} \\
& More preferred & {$[86,87]$} \\
& Higher happiness index & {$[88]$} \\
\hline
\end{tabular}

GSI Green Stormwater Infrastructure

two components of GSI that are linked with well-being indicators: biodiverse plantings and vacant lot redesigns.

We sought to understand how people react to biodiverse plantings because GSI, such as green roofs, rain gardens, and bioswales, often include native and ecological plantings and are more likely to be biodiverse [89]. One study reported that biodiverse landscapes can reduce stress in the same way that conventional landscapes do, and thus it does no harm to create landscapes with biodiversity [12]. Two studies have shown a relationship between higher biodiversity and preference. One reported the relationship between biodiversity and attractiveness: the more biodiverse a planting, the more likely people are to find it attractive [86]. The other reported higher levels of happiness from spending time walking and looking at plants in a biodiverse area than in other areas within the same park [88].

We also found studies comparing 'messy' plantings and geometric plantings, which could help to recommend how new GSI is designed and implemented. Newer forms of GSI often include more species richness and natural plantings; some people describe such plantings as 'messy'. An experimental study exploring the nature of plantings found that redesigning urban vacant lots to include organized components, such as trees and mowed grass instead of weeds, reduced crime rates [49]. A study in Germany investigated differences in the perceptions of urban vacant spaces by landscape planners and laypeople and reported that both groups liked species richness; however, laypeople preferred formal
Fig. 4 Recent evidence regarding the relationships between types of Green Stormwater Infrastructure (GSI) and human health

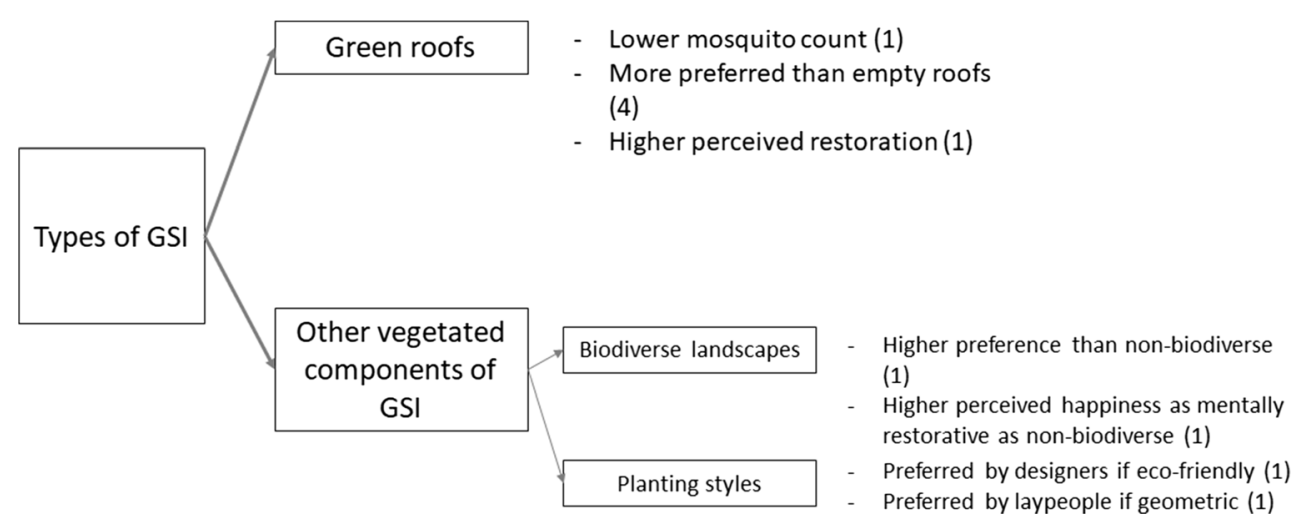


parks with well-trimmed plants and geometrical designs while landscape planners prefer more natural-looking areas. However, laypeople were willing to visit vacant lots with wild-looking vegetation if maintenance and accessibility is provided [87].

Overall, there is little research showing that newer types of GSI are associated with positive health outcomes. Still, we found some promising results regarding attention restoration with green roofs, crime reduction with rain gardens and bioswales, and attractiveness with green roofs, wellmaintained landscapes, and biodiversity. We need more evidence to understand the relationships between GSI, preference, and human health.

\section{Discussion}

In this systematic review, we found evidence that GI is associated with health benefits related to the body, mind, and human behavior. These health benefits come from living in an area with dense tree cover and green spaces, walking in green spaces or under a tree canopy, or viewing videos or images of green spaces and trees. We summarize the key findings here.

First, we found that a large body of evidence indicates that exposure to spaces including GI helps people recover from stress more quickly than spaces that do not contain GI; it reduces levels of the stress hormone cortisol and reduces a range of physiological measures of stress such as skin temperature, skin conductance, and heart rate variability. These findings have implications for the immediate and long-term health of individuals.

There are other benefits associated with exposure to GI. For example, it helps people recover from mental fatigue, improving attentional functioning and self-regulation. Exposure to GI is also associated with lower risks to mental health, such as depression, anxiety, and mood disorders. Exposure to GI is associated with reduced crime and a greater tendency for prosocial behaviors.

Secondly, we explored the types of GI being studied in such relationships. We found trees and tree density to be the most studied and provide a wide variety of health benefits such as lower rates of crime, obesity, cardiovascular diseases, and mental health symptoms. We also found green open spaces to have benefits toward cognitive functioning and mental health.

A small number of studies exploring newer forms of GI (GSI) suggest they may be linked with reduced crime and attention restoration, and that people prefer gardens with higher biodiversity and green roofs that match the architecture of the building. Much more research is needed to verify these findings and to show how GSI impacts human health.

One thing we found notable is how little GSI is represented in the studies regarding the relationships between
GI and human health. There are a few possibilities for why that might be the case. First, trees are the main types of GSI we have in the city: because rain gardens, bioswales, and green roofs are relatively new, studies involving these GSI types are being conducted and have not been fully reported yet. Secondly, the newer types of GSI are not as accessible and recognizable as trees and open spaces. Rain gardens, green roofs, and bioswales have various looks, sizes, plant species, and arrangements. To study the health benefits of these types of GSI, one must recognize how to measure their components as independent variables, which is a challenging process.

Many of these GSI types are small elements within a larger system that might include other GSI. For example, some street trees have rain gardens underneath them. Studying these GSI outside of this larger context may not be an effective way of studying them; instead, it may be more effective to study these GSI types in a park or neighborhood context.

This review presents recent findings regarding the relationships between GI and human well-being. Our review confirmed the results of some of the existing studies regarding how GI benefits human health and also provided answers to some of the questions raised by past reviews relating to the types of GI that benefit health [76]. We noted the increased frequency of dose of nature, especially density, being implemented in studies and that researchers have started to use continuous measures to study the quantity of GI. We conclude our findings by providing a visual model for studying these relationships in the future (Fig 5). Studies are now more specific about the type of GI, how much, how long, and what type of GI gains what benefits; in Fig. 5 we provide a review of the strength of the evidence in those specific relationships, which researchers can use to build their inquiries on in the future.

Based on this review, we make the following recommendations for designers and planners. First, designers should preserve and plant as many trees as possible and maximize the amount of green spaces in cities. We can see from our review that trees in urban environments have high benefits to human health $[15,40]$. Secondly, we should focus GI resources on low-income and high-crime environments where exposure to GI is most needed and may have the greatest impact, as seen in the results of various studies. GI mitigates the crime rate and stress that might come from living in a deprived community $[21,49,50]$. Designers should also design indoor spaces so that people have views of trees and green spaces because window views to green spaces have positive effects on mental restoration $[13,35]$, although the amount of nature required for this benefit is still unclear and needs to be studied further. Thus, designers and planners should work with GI researchers to find the optimal types and sizes of GI to implement for both ecological and human health purposes. Finally, because GI benefits several population types, designers should infuse urban areas with trees, 
Fig. 5 Strength of the evidence demonstrating impacts of various categories of Green Infrastructure (GI) on human health and wellbeing. Thick lines show the evidence we are confident about; thin lines show the promising links, and dashed lines require more evidence before further conclusions

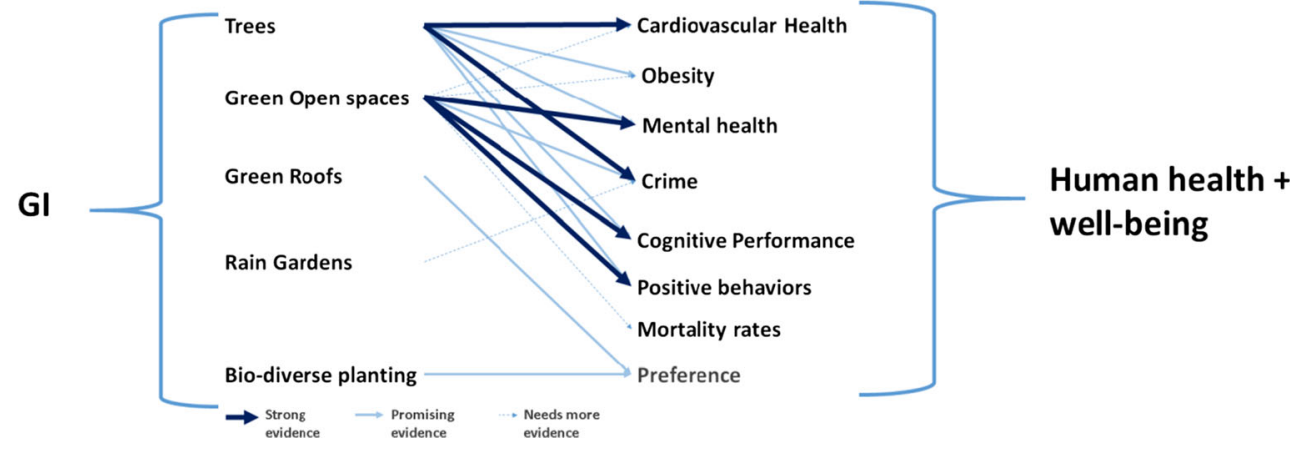

green spaces, and other forms of GI so that workers [19], students [13], mothers [90], and people who have mental issues [32] have easy access to GI.

Although we have confidence in the findings presented here, a number of questions remain. Future research should explore the following questions:

1. What is the impact of varying levels of exposure to various forms of GI? That is, how do variations in the dose of nature (e.g., the density of GI, the frequency of exposure, or the duration of exposure) impact health, functioning, and well-being in people? In this study, we found that tree density levels are related to health outcomes, but few studies explain the form of the relationships. No study was found that reported the density of other types of GI and health, the frequency of GIs' effects on health, or varying time of exposure to GI and health outcomes.

2. How do people perceive various types of GI, especially GSI, and which types do they prefer? Are there cultural or demographic differences in such perceptions? We know that people prefer green roofs, but there are two conflicting studies about what type of green roofs are preferred. These studies came from two different cultures (Australia and the USA). Researchers must explore preference for the other types of GI as well.

3. To what extent do the more ecologically healthy forms of GSI (e.g., those with considerable biodiversity) impact human health and well-being? We know, from this review, that biodiverse landscapes are more preferred than conventional landscape. However, only one study shows that a biodiverse landscape can impact stress recovery (but in no different capacity than conventional landscapes) [12]. Can we reap direct health benefits from more ecologically healthy environments, and, if so, to what extent?

4. With the exception of studies that focused on GSI, selfreported studies and qualitative studies were excluded from this review. As a consequence, we may have missed some benefits that can only be explored with self-reported results such as mood and social cohesion. What might the evidence be regarding the relationship between GI, and especially GSI, and these self-reported health outcomes?
5. The studies we found were completed in countries with predominantly western cultures. Although humans have similar physiological characteristics, culture surely impacts how our bodies and minds respond to GI. To what extent does culture impact human health responses to GI?

While there are not many studies regarding GSI, it is important to study and implement them. The main reason GSI is implemented is for its ecological benefits. However, the health and well-being impacts of these natural elements should still be studied. If we are to minimize the spread of urbanization, spaces within cities are extremely valuable, and thus we must understand how people perceive and gain health consequences from all types of GI, including GSI. As designers, planners, and researchers, one must strive to create the landscape that could both be beneficial to humans in health and infrastructure as well as mitigate the impact that the urban environment has created towards the ecosystem.

In summary, most of the previous literature reviews examining the impact of GI on human health have found that GI in general impacts health and well-being. The findings of this review show that for some of the specific categories of GI, such as trees, considerable evidence exists regarding impacts on human health. However, for other categories, such as rain gardens, green roofs, or biodiverse plantings, there is scant evidence of health impact. We believe it is likely that these forms of GI do impact human health and that the reason for the scarcity of evidence is that few careful studies have examined the impacts of newer forms of GI on specific human health outcomes. Thus, for scholars working on understanding the impacts of GI on human health, there are rich opportunities to learn more about the health implications of GI.

\section{Conclusion}

This review examined a growing body of evidence demonstrating that exposure to GI is positively associated with human health. The GI categories examined include trees, green spaces, rain gardens, bioswales, green roofs, and biodiverse plantings. Recent findings demonstrate that exposure to trees 
and easy access to green spaces is associated with a variety of health benefits. Although new evidence is emerging about the specific health benefits associated with GI, we know little about the health impacts that grow from exposure to newer types of GI, such as green roofs, rain gardens, and bioswales. There is considerable need for future research on the health impacts of these forms of GI. Given that recent studies have found that people generally prefer these forms of GI, it is reasonable to predict that exposure to green roofs, rain gardens, and bioswales has positive impacts on human health. Thus, this is an area ripe for future research.

As the human population continues to increase toward eight, then nine, and perhaps ten billion people, there will be a growing need to design settlements that are rich with nature. The results of this review suggest we should be finding ways to ensure there is GI at every doorstep.

\section{Compliance with Ethical Standards}

Conflict of Interest Statement On behalf of all authors, the corresponding author states that there are no conflicts of interest.

Human and Animal Rights and Informed Consent This article does not contain any studies with human or animal subjects performed by any of the authors.

\section{References}

1. Kaplan R, Kaplan S. The experience of nature: a psychological perspective. New York: Cambridge University Press; 1989.

2. Kuo FE, Sullivan WC. Aggression and violence in the inner city: effects of environment via mental fatigue. Environ Behav. 2001;33(4):543-71.

3. Kuo FE, Sullivan WC. Environment and crime in the inner city does vegetation reduce crime? Environ Behav. 2001;33(3):343-67.

4. Tzoulas K, Korpela K, Venn S, Yli-Pelkonen V, Kaźmierczak A, Niemela J, et al. Promoting ecosystem and human health in urban areas using green infrastructure: A literature review. Landsc Urban Plan. 2007;61(3):11.

5. Hartig T, Mitchell R, de Vries S, Frumkin H. Nature and Health. Ann Rev Public Health. 2014;35(21):207-28.

6. Coutts C, Hahn M. Green Infrastructure, Ecosystem Services, and Human Health. Int J Environ Res Public Health. 2015;12(8):976898. https://doi.org/10.3390/ijerph120809768.

7. Ulrich RS. Biophilia, Biophobia, and Natural Landscapes. In: Wilson EO, Kellert SR, editors. The Biophilia Hypothesis. Washington DC: Island Press; 1993. p. 74-137.

8. Korpela K, Hartig T. Restorative qualities of favorite places. J Environ Psychol. 1996;16(3):221-33.

9. Thomson I. EndNote 7.[CD-ROM]. Berkeley: ISI ResearchSoft; 2003.

10. Ohly H, White MP, Wheeler BW, Bethel A, Ukoumunne OC, Nikolaou V, et al. Attention Restoration Theory: A systematic review of the attention restoration potential of exposure to natural environments. J Toxicol Environ Health Part B. 2016;19(7):305-43.

11. Wang X, Rodiek S, Wu C, Chen Y, Li Y. Stress recovery and restorative effects of viewing different urban park scenes in Shanghai, China. Urban For Urban Green. 2016;15:112-22.
12. Chang KG, Sullivan WC, Lin Y-H, Su W, Chang C-Y. The Effect of Biodiversity on Green Space Users' Wellbeing-An Empirical Investigation Using Physiological Evidence. Sustainability. 2016;8(10):1049.

13. Li D, Sullivan WC. Impact of views to school landscapes on recovery from stress and mental fatigue. Landsc Urban Plan. 2016;148: 149-58.

14. Brown DK, Barton JL, Gladwell VF. Viewing nature scenes positively affects recovery of autonomic function following acutemental stress. Environ Sci Technol. 2013;47(11):5562-9.

15. Donovan GH, Butry DT, Michael YL, Prestemon JP, Liebhold AM, Gatziolis D, et al. The relationship between trees and human health: evidence from the spread of the emerald ash borer. Am J Prev Med. 2013;44(2):139-45.

16. Grazuleviciene R, Dedele A, Danileviciute A, Vencloviene J, Grazulevicius T, Andrusaityte S, et al. The influence of proximity to city parks on blood pressure in early pregnancy. Int J Environ Res Public Health. 2014;11(3):2958-72.

17. Markevych I, Thiering E, Fuertes E, Sugiri D, Berdel D, Koletzko $\mathrm{S}$, et al. A cross-sectional analysis of the effects of residential greenness on blood pressure in 10-year old children: results from the GINIplus and LISAplus studies. BMC Public Health. 2014;14(1):1.

18. Pilotti M, Klein E, Golem D, Piepenbrink E, Kaplan K. Is viewing a nature video after work restorative? Effects on blood pressure, task performance, and long-term memory. Environ Behav. 2015;47(9): 947-69.

19. Gidlow CJ, Randall J, Gillman J, Smith GR, Jones MV. Natural environments and chronic stress measured by hair cortisol. Landsc Urban Plan. 2016;148:61-7.

20. Jiang B, Li D, Larsen L, Sullivan WC. A Dose-Response Curve Describing the Relationship Between Urban Tree Cover Density and Self-Reported Stress Recovery. Environment and Behavior, 2014;48(4):607-29. https://doi.org/10.1177/0013916514552321.

21. Roe JJ, Thompson CW, Aspinall PA, Brewer MJ, Duff EI, Miller D, et al. Green space and stress: Evidence from cortisol measures in deprived urban communities. Int J Environ Res Public Health. 2013;10(9):4086-103.

22. Thompson CW, Roe J, Aspinall P, Mitchell R, Clow A, Miller D. More green space is linked to less stress in deprived communities: Evidence from salivary cortisol patterns. Landsc Urban Plan. 2012;105(3):221-9.

23. Hystad P, Davies HW, Frank L, Van Loon J, Gehring U, Tamburic $\mathrm{L}$, et al. Residential greenness and birth outcomes: evaluating the influence of spatially correlated built-environment factors. Environ Health Perspect. 2015;122:1095-102.

24. Dadvand P, Sunyer J, Basagaña X, Ballester F, Lertxundi A, Fernández-Somoano A, et al. Surrounding greenness and pregnancy outcomes in four Spanish birth cohorts. Environ Health Perspect. 2012;120(10):1481.

25. Grazuleviciene R, Danileviciute A, Dedele A, Vencloviene J, Andrusaityte S, Uždanaviciute I, et al. Surrounding greenness, proximity to city parks and pregnancy outcomes in Kaunas cohort study. Int J Hyg Environ Health. 2015;218(3):358-65.

26. Donovan GH, Michael YL, Butry DT, Sullivan AD, Chase JM. Urban trees and the risk of poor birth outcomes. Health \& place. 2011;17(1):390-3.

27. Fuertes E, Markevych I, von Berg A, Bauer C-P, Berdel D, Koletzko S, et al. Greenness and allergies: evidence of differential associations in two areas in Germany. J Epidemiol Community Health. 2014;68:787-90. http://doi.org/jech-2014-203903

28. Lovasi GS, Schwartz-Soicher O, Quinn JW, Berger DK, Neckerman KM, Jaslow R, et al. Neighborhood safety and green space as predictors of obesity among preschool children from lowincome families in New York City. Prev Med. 2013;57(3):189-93. 
29. Villeneuve PJ, Jerrett M, Su JG, Burnett RT, Chen H, Wheeler AJ, et al. A cohort study relating urban green space with mortality in Ontario, Canada. Environ Res. 2012;115:51-8.

30. Kim J-H, Lee C, Sohn W. Urban Natural Environments, Obesity, and Health-Related Quality of Life among Hispanic Children Living in Inner-City Neighborhoods. Int J Environ Res Public Health. 2016;13(1):121.

31. Wolch J, Jerrett M, Reynolds K, McConnell R, Chang R, Dahmann $\mathrm{N}$, et al. Childhood obesity and proximity to urban parks and recreational resources: a longitudinal cohort study. Health Place. 2011;17(1):207-14.

32. Berman MG, Kross E, Krpan KM, Askren MK, Burson A, Deldin $\mathrm{PJ}$, et al. Interacting with nature improves cognition and affect for individuals with depression. J Affect Disord. 2012;140(3):300-5.

33. Bratman GN, Daily GC, Levy BJ, Gross JJ. The benefits of nature experience: Improved affect and cognition. Landsc Urban Plan. 2015;138:41-50.

34. Shin WS, Shin CS, Yeoun PS, Kim JJ. The influence of interaction with forest on cognitive function. Scand J For Res. 2011;26(6):595-8.

35. Lee KE, Williams KJ, Sargent LD, Williams NS, Johnson KA. 40second green roof views sustain attention: The role of micro-breaks in attention restoration. J Environ Psychol. 2015;42:182-9.

36. Beute F, de Kort Y. Natural resistance: Exposure to nature and selfregulation, mood, and physiology after ego-depletion. J Environ Psychol. 2014;40:167-78.

37. Wu C-D, McNeely E, Cedeno-Laurent J, Pan W-C, Adamkiewicz $\mathrm{G}$, Dominici F et al. Linking student performance in Massachusetts elementary schools with the "greenness" of school surroundings using remote sensing. 2014.

38. Dadvand P, Nieuwenhuijsen MJ, Esnaola M, Forns J, Basagaña X, Alvarez-Pedrerol M, et al. Green spaces and cognitive development in primary schoolchildren. Proc Natl Acad Sci. 2015;112(26): 7937-42.

39. Nutsford D, Pearson A, Kingham S. An ecological study investigating the association between access to urban green space and mental health. Public Health. 2013;127(11):1005-11.

40. Taylor MS, Wheeler BW, White MP, Economou T, Osborne NJ. Research note: urban street tree density and antidepressant prescription rates - a cross-sectional study in London, UK. Landsc Urban Plan. 2015;136:174-9.

41. Flouri E, Midouhas E, Joshi H. The role of urban neighbourhood green space in children's emotional and behavioural resilience. J Environ Psychol. 2014;40:179-86.

42. Balseviciene B, Sinkariova L, Grazuleviciene R, Andrusaityte S, Uzdanaviciute I, Dedele A, et al. Impact of residential greenness on preschool children's emotional and behavioral problems. Int J Environ Res Public Health. 2014;11(7):6757-70.

43. Troy A, Grove JM, O'Neil-Dunne J. The relationship between tree canopy and crime rates across an urban-rural gradient in the greater Baltimore region. Landsc Urban Plan. 2012;106(3):262-70.

44. Wolfe MK, Mennis J. Does vegetation encourage or suppress urban crime? Evidence from Philadelphia, PA. Landsc Urban Plan. 2012;108(2):112-22.

45. Troy A, Nunery A, Grove JM. The relationship between residential yard management and neighborhood crime: An analysis from Baltimore City and County. Landsc Urban Plan. 2016;147:78-87.

46. Branas CC, Cheney RA, MacDonald JM, Tam VW, Jackson TD, Ten Have TR. A difference-in-differences analysis of health, safety, and greening vacant urban space. Am J Epidemiol. 2011:kwr273.

47. Du Y, Law J. How Do Vegetation Density and Transportation Network Density Affect Crime across an Urban CentralPeripheral Gradient? A Case Study in Kitchener-Waterloo, Ontario. ISPRS Int J Geo Inf. 2016;5(7):118.

48. Donovan GH, Prestemon JP. The effect of trees on crime in Portland, Oregon. Environ Behav. 2012;44(1):3-30.
49. Kondo MC, Hohl B, Han S, Branas C. Effects of greening and community reuse of vacant lots on crime. Urban Studies. 2015: 0042098015608058.

50. Kondo MC, Han S, Donovan GH, MacDonald JM. The association between urban trees and crime: Evidence from the spread of the emerald ash borer in Cincinnati. Landsc Urban Plan. 2017;157: 193-9.

51. Berry MS, Sweeney MM, Morath J, Odum AL, Jordan KE. The nature of impulsivity: Visual exposure to natural environments decreases impulsive decision-making in a delay discounting task. PLoS One. 2014;9(5):e97915.

52. Guéguen N, Stefan J. "Green Altruism" Short Immersion in Natural Green Environments and Helping Behavior. Environ Behav. 2016;48(2):324-42.

53. Piff PK, Dietze P, Feinberg M, Stancato DM, Keltner D. Awe, the small self, and prosocial behavior. J Pers Soc Psychol. 2015;108(6):883.

54. Ng HKS. Chow TS. The effects of environmental resource and security on aggressive behavior. Aggress Behav. 2016.

55. Kuo FE. How might contact with nature promote human health? Exploring promising mechanisms and a possible central pathway. Front Psychol. 2015;6:1093.

56. Ulrich RS. View through a window may influence recovery from surgery. Science. 1984;224(4647):420-1. https://doi.org/10.1126/ science.6143402.

57. Ulrich RS, Simons RF, Losito BD, Fiorito E, Miles MA, Zelson M. Stress recovery during exposure to natural and urban environments. J Environ Psychol. 1991;11(3):201-30.

58. Juster R-P, McEwen BS, Lupien SJ. Allostatic load biomarkers of chronic stress and impact on health and cognition. Neurosci Biobehav Rev. 2010;35(1):2-16.

59. Ulrich RS. Aesthetic and affective response to natural environment. In: Altman I, Wohlwill JF, editors. Behavior and the natural environment. Human behavior and environment (advances in theory and research), vol. 6. Boston: Springer; 1983. p. 85-125.

60. Kyrou I, Tsigos C. Chronic stress, visceral obesity and gonadal dysfunction. Hormones (Athens). 2008;7(4):287-93.

61. Kuo LE, Czarnecka M, Kitlinska JB, Tilan JU, Kvetňanský R, Zukowska Z. Chronic Stress, Combined with a High-Fat/HighSugar Diet, Shifts Sympathetic Signaling toward Neuropeptide Y and Leads to Obesity and the Metabolic Syndrome. Ann N Y Acad Sci. 2008;1148:232-7. https://doi.org/10.1196/annals.1410.035.

62. Lovasi GS, O'Neil-Dunne JP, Lu JW, Sheehan D, Perzanowski MS, MacFaden SW, et al. Urban tree canopy and asthma, wheeze, rhinitis, and allergic sensitization to tree pollen in a New York City birth cohort. Environ Health Perspect (Online). 2013;121(4):494.

63. Taylor AF, Kuo FE, Sullivan WC. Views of nature and self-discipline: Evidence from inner city children. J Environ Psychol. 2002;22(1):49-63.

64. Kaplan S. The restorative benefits of nature: Toward an integrative framework. J Environ Psychol. 1995;15(3):169-82.

65. Kuo FE, Sullivan WC, Coley RL, Brunson L. Fertile ground for community: Inner-city neighborhood common spaces. Am J Community Psychol. 1998;26(6):823-51.

66. Brunson L, Kuo FE, Sullivan WC. Resident Appropriation of Defensible Space in Public Housing Implications for Safety and Community. Environ Behav. 2001;33(5):626-52.

67. Baumeister RF, Vohs KD. Self-regulation and the executive function of the self. In: Leary MR, Tangney JP, editors. Handbook of self and identity. Guilford Publications in New York. 2003;1:197217.

68. Taylor AF, Kuo FE, Sullivan WC. Coping with ADD The surprising connection to green play settings. Environ Behav. 2001;33(1): 54-77. 
69. Corbett JB. Altruism, self-interest, and the reasonable person model of environmentally responsible behavior. Sci Commun. 2005;26(4):368-89.

70. Kweon B-S, Sullivan WC, Wiley AR. Green common spaces and the social integration of inner-city older adults. Environ Behav. 1998;30(6):832-58.

71. Kondo MC, Low SC, Henning J, Branas CC. The impact of green stormwater infrastructure installation on surrounding health and safety. Am J Public Health. 2015;105(3):e114-e21.

72. Kuo FE, Bacaicoa M, Sullivan WC. Transforming inner-city landscapes trees, sense of safety, and preference. Environ Behav. 1998;30(1):28-59.

73. Kaplan R, Kaplan S. Well-being, Reasonableness, and the Natural Environment. Appl Psychol: Health Well Being. 2011;3(3):304-21. https://doi.org/10.1111/j.1758-0854.2011.01055.x.

74. Nancy B, James P, Rickie B, Dalton P. Environmental and occupational respiratory disorders: The asthma and obesity epidemics: The role played by the built environment - a public health perspective. J Allergy Clin Immunol. 115:1024-8. https://doi.org/10.1016/j.jaci. 2005.02.020.

75. Thompson C, Ward RJ, Aspinall P, Mitchell R, Clow A, Miller D. More green space is linked to less stress in deprived communities: Evidence from salivary cortisol patterns. Landsc Urban Plan. 2012;105:9.

76. Sullivan WC, Frumkin H, Jackson RJ, Chang C-Y. Gaia meets Asclepius: Creating healthy places. Landsc Urban Plan. 2014;127:182-4.

77. Ward Thompson C, Travlou P. In: Ward Thompson C, Travlou P, editors. Open space : people space. London; New York: Taylor and Francis; 2007.

78. Barton J, Pretty J. What is the best dose of nature and green exercise for improving mental health? A multi-study analysis. Environ Sci Technol. 2010;44(10):3947-55.

79. Baumeister RF, Vohs KD. Self-Regulation, ego depletion, and motivation. Soc Personal Psychol Compass. 2007;1(1):115-28.
80. Bratman GN, Hamilton JP, Daily GC. The impacts of nature experience on human cognitive function and mental health. Ann N Y Acad Sci. 2012;1249(1):118-36.

81. Wong GK, Jim C. Do vegetated rooftops attract more mosquitoes? Monitoring disease vector abundance on urban green roofs. Sci Total Environ. 2016;573:222-32.

82. White EV, Gatersleben B. Greenery on residential buildings: Does it affect preferences and perceptions of beauty? J Environ Psychol. 2011;31(1):89-98.

83. Jungels J, Rakow DA, Allred SB, Skelly SM. Attitudes and aesthetic reactions toward green roofs in the Northeastern United States. Landsc Urban Plan. 2013;117:13-21.

84. Loder A. 'There's a meadow outside my workplace': A phenomenological exploration of aesthetics and green roofs in Chicago and Toronto. Landsc Urban Plan. 2014;126:94-106.

85. Lee KE, Williams KJ, Sargent LD, Farrell C, Williams NS. Living roof preference is influenced by plant characteristics and diversity. Landsc Urban Plan. 2014;122:152-9.

86. Lindemann-Matthies P, Marty T. Does ecological gardening increase species richness and aesthetic quality of a garden? Biol Conserv. 2013;159:37-44.

87. Hofmann M, Westermann JR, Kowarik I, van der Meer E. Perceptions of parks and urban derelict land by landscape planners and residents. Urban For Urban Green. 2012;11(3):303-12.

88. Adjei PO-W, Agyei FK. Biodiversity, environmental health and human well-being: analysis of linkages and pathways. Environ Dev Sustain. 2015;17(5):1085-102.

89. USEPA. What is green infrastructure? 2015. https://www.epa.gov/ green-infrastructure/what-green-infrastructure. 2016.

90. McEachan R, Prady S, Smith G, Fairley L, Cabieses B, Gidlow C, et al. The association between green space and depressive symptoms in pregnant women: moderating roles of socioeconomic status and physical activity. J Epidemiol Community Health. 2016;70: 253-9. http://doi.org/jech-2015-205954 